\title{
Technical equipment of agricultural production in the region and factors influencing its development
}

\author{
Tuyana Baiaskalanova ${ }^{1, *}$, Vladimir Kabakov $^{2}$, and Olga Kabakova ${ }^{2}$ \\ ${ }^{1}$ Irkutsk National Research Technical University, 664074, Lermontova str., 83., Irkutsk, Russia \\ ${ }^{2}$ Novosibirsk State Agrarian University, 630039, Dobrolubov str., 160, Novosibirsk, Russia
}

\begin{abstract}
The definition of the concept of technical equipment and identification of the level of technical equipment of agriculture in the Novosibirsk region is dealt with in this paper. The analysis of the technical equipment of agricultural production with machinery and mechanisms has been conducted. The study of literature sources on definition of the concept of technical equipment of agricultural production has been carried out. Statistical data on the availability of agricultural machinery for agricultural producers in the region, and the structure of energy capacities have been analyzed. The data on the renewal of agricultural machinery and the volume of production of plant growing and livestock are graphically presented. The factors influencing the technical equipment of agricultural production and the degree of their influence on the efficiency of the agricultural production of the region are revealed. The ways of improving the system of technical equipment are suggested. The model of the dependence of the efficiency of agricultural production on its technical equipment is substantiated with the help of economic and mathematical modeling in order to obtain more accurate data on the region's need for agricultural machinery.
\end{abstract}

\section{Introduction}

In agricultural production, the problem of increasing labor productivity and modernization is mainly being solved now by using the latest technologies and modern equipment, which has a fundamental importance for increasing competitiveness of the Russian agricultural producers.

In order to raise competitiveness of the agricultural sector, the state sets the task of increasing technical equipment of production. In Russia as a whole and in its regions in particular, the state and regional agriculture development programs are being adopted with regards to the technical equipping of the agricultural production with machinery.

Within the framework of the state development program to the year 2020, the subprogram "Technical and technological modernization and innovative development", which purpose is to increase the efficiency and competitiveness of the agricultural producers'

*Corresponding author: dama83@ mail.ru 
products through technical and technological modernization of production, sets the following objectives: stimulating the acquisition of high-tech machinery and equipment by the agricultural producers; increasing innovation activity of the agricultural producers, and expanding the scale of agricultural development on the innovative basis.

In the Novosibirsk region, the Ministry of Agriculture proposes ways to improve the level of technical equipment that are the components of the agriculture development programs in the region.

Before forming a strategy or a program for the development of agriculture, it is necessary to take into account the influence of many factors on the performance of enterprises and the region as a whole. It is needed to conduct a correlation-regression analysis of the influence of various factors on the technical equipment, and to identify the most significant factors for increasing competitiveness of this industry in the region.

\section{Problem statement}

The purpose of the research is to study the state of modernization of the agricultural production with up-to-date technical means, equipment and machinery, and the identification of the most significant factors affecting the technical equipment of agricultural production.

The object of the study is the technical equipment of agricultural production in the Novosibirsk region. In course of the analysis, the authors have used abstract-logical, economic-statistical and graphical methods of research.

\section{Theories}

Various working processes are the objects of mechanization in the agricultural production, such as soil cultivation, sowing, fertilizing, combating diseases and pests, processing grain, harvesting and distributing feed, cleaning livestock premises, milking cows, shearing, repairing agricultural machinery, and processing agricultural products [17-18, for instance].

Many scientists, such as S.N. Sazonov, A.A. Polukhin, V.T. Vodyannikov, A.S. Shelepa et al [1-9] were engaged in studying the problems of technical equipment of the agricultural producers with agricultural machinery. The analysis of literature sources showed that there is no definition of the term "technical equipment" in publications. In the dictionary of the Russian language, equipment is understood as the degree of equipping of something.

I.V. Shatokhin et al. [10] reveal the interconnection of the technical equipment of grain production with the volumes of products produced and provide yield data for individual soil and climatic zones and for the availability of agricultural machinery in the zones under studies. The authors clearly demonstrate the yield and equipment of the machine and tractor fleet, but do not provide economic and mathematical calculations of the dependence of production volumes on the technical equipment.

I.V. Shagurov and A.M. Matveev [11] associate technical equipment with a reduction of the costs for repair and operation due to the introduction of optimal energy resources for aggregating modular planting complexes with them, that is, due to new technologies of grain cultivation in combination with the optimally selected system of machines, the technical equipment will grow. This approach is economically feasible, but insufficient attention is paid to the calculation of technical equipment indicators.

V.I. Dragaitsev [12], when calculating the technical equipment, uses the specific indicator for the availability of combines per 1000 hectares of crops of grain and other cultures. This indicator is calculated only for combines, since the author considers the harvesting process (15-20\% of the cost price) to be the most costly and machine-intensive operation in the 
technology of cultivation of grain crop. In our opinion, this approach does not fully reflect the picture of equipping the agricultural sector.

The authors of the article proposed the definition of this concept. The technical equipment of the agricultural production is the degree of providing the process of agricultural production with the equipment, machinery and mechanisms necessary for the normal operation of the enterprise in a market situation.

\section{Findings}

\subsection{Assessment of the technical equipment of the agricultural production in the region}

In agriculture, there is a tendency for obsolescence and equipment failure. In the Novosibirsk region, there is a clear shortage of energy-intensive, high-performance machinery and the introduction of resource-saving technologies using combined soil-cultivating and sowing units, which allow performing all technological operations in the normative agro-technical terms that leads to inadequate return and product losses. The technical equipment has decreased by more than $30 \%$. The provision of some machines and equipment is at the level of $50-60 \%$. Seeders, harrows and plows now belong to the category of the deficit machines. Enterprises cannot be competitive on the agricultural products market without raising the level of their technical equipment.

The experience of foreign countries and highly effective agricultural enterprises in Russia shows that this is mainly the material and technical base realized through technology and technical means that determines the increase in the efficiency of agricultural production and competitiveness of products on the domestic and foreign markets [12]. The optimal level of technical equipment makes it possible to increase the volume of production, reduce costs, and increase profitability and labor productivity.

In Russia, over the past 20 years there has been a tendency to reduction of the number of agricultural machinery. Each year, the tractors fleet has been reducing by an average of $7 \%$ and the fleet of combine harvesters by $8 \%$. In the future, it is predicted that these figures will drop to $10-12 \%$ [13]. In the Novosibirsk region, the situation with the machine and tractor fleet is similar (Table 1) [14]. First of all, this is due to the use of morally and physically obsolete equipment in the production and the lack of financial resources that experience agricultural producers to purchase new high-tech equipment.

Table 1. Availability of the basic equipment in agricultural organizations of the Novosibirsk region, thousand units.

\begin{tabular}{|l|c|c|c|c|c|c|c|}
\hline \multicolumn{1}{|c|}{ Types of equipment } & $\mathbf{2 0 1 1}$ & $\mathbf{2 0 1 2}$ & $\mathbf{2 0 1 3}$ & $\mathbf{2 0 1 4}$ & $\mathbf{2 0 1 5}$ & $\mathbf{2 0 1 6}$ & $\begin{array}{c}\mathbf{2 0 1 6} \text { as \% } \\
\text { of 2011 }\end{array}$ \\
\hline Tractors & 10.7 & 10.1 & 9.4 & 8.3 & 7.5 & 7.1 & -29.9 \\
\hline Plows & 2.9 & 2.6 & 2.5 & 2.1 & 1.9 & 1.8 & -34.4 \\
\hline Harrows & 41.2 & 38.2 & 36.0 & 31.2 & 27.3 & 25.2 & -33.7 \\
\hline Cultivators & 2.9 & 2.7 & 2.5 & 2.2 & 2.0 & 1.9 & -31.0 \\
\hline Sowing machines & 5.8 & 5.4 & 5.0 & 4.4 & 3.9 & 3.7 & -32.8 \\
\hline Combine harvesters & 3.4 & 3.1 & 2.8 & 2.5 & 2.2 & 2.1 & -35.3 \\
\hline Feeder harvesters & 0.8 & 0.8 & 0.7 & 0.7 & 0.6 & 0.6 & -25.0 \\
\hline Milking plants & 1.7 & 1.7 & 1.7 & 1.6 & 1.5 & 1.5 & -11.8 \\
\hline
\end{tabular}


It is evident from the statistical data that annually the quantity of the agricultural machinery in the Novosibirsk region is reduced almost in all positions. The number of tractors decreased from 10.7 to 7.1 thousand units, grain harvesters - from 3.4 to 2.1 and forage harvesters - from 0.8 to 0.6 thousand units. Over the past six years, the amount of equipment in disposal of the agricultural producers has decreased in average by $30 \%$ (Figure 1).

In addition, there is a clear reduction of the energy capacity in the agricultural organizations (Table 2). Thus, a decrease in the total power of the engines of tractors from 1.23 to 0.90 million $\mathrm{HP}$, of combines and self-propelled machines from 0.66 to 0.53 million HP was noted. In average for the last six years, the energy capacity was reduced by $20.7 \%$.

Table 2. Availability of the energy capacity in the agricultural organizations in the Novosibirsk region, million HP.

\begin{tabular}{|l|c|c|c|c|c|c|c|}
\hline \multicolumn{1}{|c|}{ Energy capacity } & $\mathbf{2 0 1 1}$ & $\mathbf{2 0 1 2}$ & $\mathbf{2 0 1 3}$ & $\mathbf{2 0 1 4}$ & $\mathbf{2 0 1 5}$ & $\mathbf{2 0 1 6}$ & $\begin{array}{c}\mathbf{2 0 1 6} \text { as \% } \\
\text { of 2011 }\end{array}$ \\
\hline Total energy capacity & 3.44 & 3.30 & 3.16 & 2.89 & 2.69 & 2.63 & -20.6 \\
\hline \multicolumn{7}{|c|}{ Total rated power } \\
\hline engines of tractors & 1.23 & 1.18 & 1.12 & 1.01 & 0.92 & 0.90 & -250 \\
\hline $\begin{array}{c}\text { engines of combines and } \\
\text { self-propelled machines }\end{array}$ & 0.66 & 0.63 & 0.61 & 0.56 & 0.53 & 0.53 & -28.6 \\
\hline engines of cars & 1.00 & 1.00 & 0.95 & 0.87 & 0.81 & 0.78 & -20.0 \\
\hline $\begin{array}{c}\text { other mechanical } \\
\text { engines }\end{array}$ & 0.04 & 0.04 & 0.04 & 0.03 & 0.03 & 0.03 & -25.0 \\
\hline $\begin{array}{c}\text { electric motors and } \\
\text { electrical installations }\end{array}$ & 0.49 & 0.46 & 0.43 & 0.40 & 0.39 & 0.37 & -20.0 \\
\hline
\end{tabular}

Reduction of the machine and tractor fleet, and decrease of the energy supply of the agricultural enterprises lead to a decrease in the quantity of cultivated areas of the farmland. Over the past 5 years, there was a release of the crop areas by $4 \%$, and in general for the farmland - by $1 \%$.

In the Novosibirsk region, the reduction in the number of agricultural machinery is primarily connected with the withdrawal of equipment due to its moral and physical deterioration, and the lack of funds that experience agricultural producers to purchase a new one. In the USA and Germany, there is also a reduction in the machine and tractor fleet [12], but at the same time, the power capacities are growing. This indicates that the released machinery is replaced by new progressive one, more powerful and productive.

In the developed countries, there is ongoing an active process of updating the technical park by replacing old machines with more productive and intellectual equipment [15]. Improvements in the field of electronics, sensory technology and software, their active use in the designs of modern agricultural machinery determine the nature of the agricultural technical innovations that lead to the increased competitiveness of foreign agricultural producers on the market of agricultural products.

In the Novosibirsk region, there was the target program "Technical re-equipment of agricultural production in the Novosibirsk region for 2008-2012", the tasks of which were to stimulate the agricultural producers to the acquisition of high-tech machinery and equipment, and also to maintain the agricultural machinery and equipment in a proper technical condition. However, the results of the study suggest that the power consumption in the Novosibirsk region continues to decline, the ratio of renewal of the agricultural machinery continues to fall in average (Figure 2), and the average power of a single tractor is practically unchanged. Therefore, it is impossible to talk about the receipt of more powerful equipment. 
As it can be seen from the Figure 2, the trend line on the renewal of agricultural machinery has a downward trend. So, in terms of the tractors, the renewal coefficient for five years, from 2011 to 2016, decreased from 2.7 to $1.4 \%$, respectively. The deficit of modern agricultural machinery has become one of the main reasons restraining the development of the agricultural production in the Novosibirsk region.
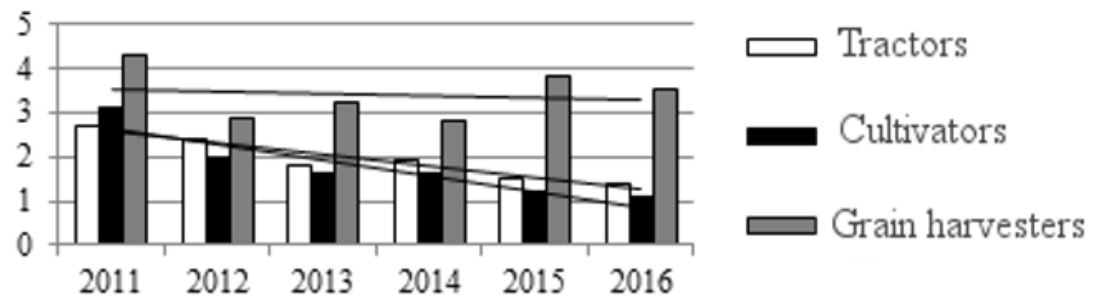

Fig. 2. Coefficients of renewal of some types of agricultural machinery in the Novosibirsk region.

P. A. Tabakov [16] revealed the pattern of influence of technical equipment on the efficiency of agricultural production. The higher is the technical equipment and power-toweight ratio, the greater is the gross profit of enterprises. In our case, according to the results of the study, gross agricultural output is growing in money terms, while the volume of agricultural production is declining (Table 3 ). The increase in the gross output is connected with the change in the price level.

Table 3. Volumes of production of agricultural products of the Novosibirsk region.

\begin{tabular}{|l|c|c|c|c|c|c|}
\hline \multicolumn{1}{|c|}{ Indicators } & $\mathbf{2 0 1 1}$ & $\mathbf{2 0 1 2}$ & $\mathbf{2 0 1 3}$ & $\mathbf{2 0 1 4}$ г. & $\mathbf{2 0 1 5}$ & $\mathbf{2 0 1 6}$ \\
\hline $\begin{array}{l}\text { Gross agricultural } \\
\text { production (in actual } \\
\text { effective prices), million } \\
\text { rubles }\end{array}$ & 60424.7 & 56034.5 & 66374.1 & 71407.5 & 85296.7 & 85970.3 \\
\hline $\begin{array}{l}\text { Gross grain harvest, } \\
\text { thousand tons }\end{array}$ & 2503.3 & 1239.5 & 2292.6 & 1784.6 & 2196.5 & 2341.1 \\
\hline $\begin{array}{l}\text { Gross harvest of sunflower } \\
\text { seeds, thousand tons }\end{array}$ & 9.1 & 5.4 & 11.3 & 4.5 & 5.3 & 7.3 \\
\hline $\begin{array}{l}\text { Gross harvest of potatoes, } \\
\text { thousand tons }\end{array}$ & 617.3 & 286.8 & 550.8 & 443.5 & 504.8 & 443.0 \\
\hline Number of cattle, thousand & 552.7 & 522.3 & 490.6 & 467.4 & 471.3 & 457.5 \\
\hline Number of pigs, thousand & 372.2 & 371.9 & 340.2 & 387.5 & 383.2 & 360.4 \\
\hline
\end{tabular}

As it can be seen from the Table, the value of gross output continues to grow, while the gross grain harvest decreased by $12 \%$, potatoes by $12 \%$, from 617.3 to 443.0 thousand tones, the number of cattle decreased over the six years by an average of $15 \%$ and amounted to 457.5 thousand. Thus, a decrease in the equipping of production with machinery and equipment entails a decrease in the production and welfare of the agricultural producers.

\subsection{Analysis of the influence of various factors on the technical equipment of agricultural production}

To determine the degree of influence of the technical equipment of agricultural production on the efficiency of agricultural production in the enterprises of the Novosibirsk region, the method of multifactorial regression analysis has been used. The advantage of such a method 
is the ability to determine the relationship of the resultant trait with several factors, and to establish the degree of their influence. Similarly, the construction of the correlationregression model allows us substantiating the choice and significance of the factors. In the calculation process, their statistical reliability is established and the degree of influence of variables not included in the model is determined.

The indicator of the financial return of agricultural production has been chosen as the resultant trait, which reflects the efficiency of the use of the entire range of fixed assets, including agricultural machinery and equipment.

The following indicators have been chosen as the factor characteristics $\left(X_{i}\right)$ :

$X_{1}$ - power supply (power capacity per 100 hectares of the arable land), HP;

$X_{2}$ - capital adequacy, million rubles / thousand people;

$X_{3}$ - share of depreciation in the total costs, $\%$;

$X_{4}$ - the proportion of investment in the fixed capital in total investment, per cent;

$X_{5}$ - the number of harvesters per 1000 hectares of grain crops;

$X_{6}$ - the number of tractors per 1000 hectares of the arable land.

These indicators reflect the technical equipment of the agricultural production of the Novosibirsk region, and show the level of reproduction and renewal of the agricultural machinery and equipment, as well as the activity of agricultural enterprises in the modernization of technical potential.

As a result of the solution, the following regression equation (1) is obtained:

$$
Y=9.3392+3.817 X_{1}+0.0069 X_{2}-0.772 X_{3}-0.0496 X_{4}+0.4627 X_{5}-0.0102 X_{6}
$$

The authors have analyzed the multicollinearity of the variables $X_{i}$ on the basis of a matrix of correlation coefficients, in order to exclude duplicating factors from the model. The matrix of the paired correlation coefficients (Table 5) indicates that there is no collinearity between the factors selected for constructing the model. In our case, all the pair correlation coefficients are $|r|<0.7$ that indicates the lack of the collinear factors.

Table 5. Matrix of pair correlation coefficients R.

\begin{tabular}{|c|c|c|c|c|c|c|c|}
\hline & $\boldsymbol{Y}$ & $\boldsymbol{X}_{\mathbf{1}}$ & $\boldsymbol{X}_{\mathbf{2}}$ & $\boldsymbol{X}_{\mathbf{3}}$ & $\boldsymbol{X}_{\mathbf{4}}$ & $\boldsymbol{X}_{\mathbf{5}}$ & $\boldsymbol{X}_{\mathbf{6}}$ \\
\hline$Y$ & 1.00 & & & & & & \\
\hline$X_{1}$ & 0.05 & 1.00 & & & & & \\
\hline$X_{2}$ & -0.28 & -0.64 & 1.00 & & & & \\
\hline$X_{3}$ & -0.39 & -0.60 & 0.58 & 1.00 & & & \\
\hline$X_{4}$ & -0.28 & 0.05 & -0.30 & -0.23 & 1.00 & & \\
\hline$X_{5}$ & 0.47 & 0.52 & -0.62 & -0.60 & -0.02 & 1.00 & \\
\hline$X_{6}$ & -0.02 & 0.34 & -0.54 & -0.54 & -0.09 & 0.56 & 1.00 \\
\hline
\end{tabular}

This regression model is statistically reliable, since the actual value of the Fisher's F-test was $\mathrm{F}=14.13$ that exceeds the table value $F$ табл. $=4.53$.

The coefficient of the multiple correlation $R=0.98$ indicates that the relationship between the indicators of the financial returns and the factors chosen to build the model is strong enough. The value of the coefficient of determination $R^{2}=0.97$. The closer the coefficient of determination to 1 , the greater the regression equation explains the behavior of $Y$. It can be concluded that $97 \%$ is due to the behavior of the factors included in the model.

To optimize the constructed correlation-regression model, the authors applied a step-bystep exclusion of the variables $X_{i}$, unreliable in the Student's t-test, having a Student's tcriterion value below the normative $\left(t_{\text {critical }}=2.365\right)$. This makes it possible to obtain more reliable and statistically significant model. 
As a result of the elimination of the factors that are unreliable for the model, which have been found to be: the capital adequacy of labor workers in the agricultural enterprises $\left(X_{2}\right)$, the share of depreciation in the total costs $\left(X_{3}\right)$, the number of combines per 1000 hectares of crops $\left(X_{5}\right)$, the number of tractors per 1000 hectares of arable land $\left(X_{6}\right)$, the following multiple regression equation (2) has been obtained:

$$
Y=9.3392+3.817 X_{1}-0.0496 X_{4}
$$

Standardized partial regression coefficients ( $\beta$-coefficients) confirm a strong relationship between the factors $X_{i}$ and the resulting sign of $Y$.

Concluding the statistical study, we can argue that the provisions of the energy capacities and investments for the agricultural production are the determining factors of the profitability of the agricultural production and the competitiveness of the agricultural organizations in the region.

Thus, with an increase in the energy supply by 1 HP per 100 hectares, the profitability of agricultural production increases by $3.8 \%$. At the same time, according to the results of the regression analysis in the correlation-regression model, the coefficient of the variable $X_{4}$ (investment in the fixed assets) was -0.049 that indicates a low level of investment in the agricultural production, which leads to a decrease in the cost-effectiveness and inevitably leads to a decrease in the competitiveness of organizations on the market of the agricultural products.

\section{Conclusion}

Based on the conducted research, it is obvious that the system of measures to support agribusiness does not fully correspond to the need for investing in the agricultural sector of the economy.

Within the framework of the state program for the development of agriculture and regulation of markets for the agricultural products, raw materials and food for 2013-2020 [19], 2 billion rubles have been allocated for the sub-program "Technical and technological modernization and innovative development". Grants have been allocated for reimbursement of expenses for the purchase of agricultural machinery at a discount and according to the list approved by the Government of the Russian Federation.

In 2014 and 2015, agricultural organizations of the Novosibirsk region received loans for the amount of 169 and 225 million rubles respectively for the purchase of the agricultural equipment that is by $133.2 \%$ higher as compared to the previous period. They received leased equipment from the federal budget on the amounts of 147.02 and 174.36 million rubles [20]. However, as it can be seen from the results of the study, these financial injections are not enough to meet the demand in the innovative high-performance machinery for the needs of the agricultural producers.

In order to improve technical equipment, more effective measures of the state support for the agricultural producers are needed, oriented to the advanced technologies and the latest achievements in the field of agricultural machinery. In addition to that, an economic and mathematical model of the dependence of competitiveness of the agricultural production on its technical equipment is needed in order to obtain more accurate data on the region's demand in agricultural machinery, and in the production volumes required by the market. 


\section{References}

1. S. N. Sazonov, D. D. Sazonova, Science in the Center of Russia, 2(14), 21-34 (2015)

2. A. A. Polukhin, Agrotech. and Energy Saving, 1, 241-249 (2014)

3. V. T. Vodyannikov, P. A. Rubtsov, Vestnik of the Moscow State Agroengineering University named after V.P. Goryachkin, 3, 79-82 (2013)

4. A. Shelepa, V. V. Terekhov. V. B. Vernin, The development of innovation activities in the agro-industrial complex, 255-258 (2013)

5. V. N. Papelo, B. A. Kovtun, K. Ch. Akberov, A. I. Ternovoi,Fundamental Research, 11(5), 1017-1024 (2013)

6. A. V. Belousov, History, state and prospects of the development of agricultural economics of science and education (GAU, Voronezh, 2016)

7. S. G. Chernova, Vestn. Novosib. State. Agrarian. University, 4(45), 201-207 (2017)

8. S. A. Shelkovnikov, S. N. Matvienko, Vestn. Novosib. State. Agrarian. University, 1(34), 175-180 (2015)

9. S. V. Sharybar, Actual. Pobl. Economy, 10, 56-61 (2014)

10. I. V. Shatokhin, G. I. Haustova, L. A. Shatohina, Vestn. Voronezh. State. Agrarian. Uni., 2, 34-36 (2011)

11. I. V. Shagurov, A. M. Matveev, Vestn. Kurg. SAA, 4(12), 5-8 (2014)

12. V. I. Dragaytsev, Engineering and Equipment for the Village, 7, 30-34 (2013)

13. A. T. Stadnik, D. M. Matveev, M. G. Krokhta, Vestn. Novosib. State. Agrarian. University, 3(24), 132-135 (2012)

14. L. A. Zhiboedova, Stat. Bull., 5(15) (2016)

15. Rosinformagrotech, Modern technology and resource-saving technologies in increasing labor productivity and competitiveness of agricultural products (www.rosinfor magrotech.ru, 2018)

16. P. A. Tabakov, Engineering and Equipment for the Village, 2, 34-35 (2012)

17. A. V. Bogoviz, S. V. Lobova, Y. A. Bugai, Advances in Intelligent Systems and Computing, 622, 30-36 (2018)

18. A. V. Bogoviz, S. V. Lobova, Y. V. Ragulina, A. N. Alekseev, International Journal of Energy Economics and Policy, 8(3), 67-75 (2018)

19. Official website of the Ministry of Agriculture of the Russian Federation (http://mcx.ru/, 2018)

20. Official site of the Ministry of Agriculture of the Novosibirsk region (http://www. mcx.nso.ru, 2018) 